\title{
Cambial Variations of Three Lianoid Genera, Akebia, Stauntonia, and Sabia (Lardizabalaceae and Sabiaceae), in Taiwan
}

\author{
Sheng-Zehn Yang1 ${ }^{*}$, Po-Hao Chen ${ }^{1}$, Jian-Jhong Chen ${ }^{2}$ \\ ${ }^{1}$ National Pingtung University of Science and Technology, Taiwan \\ ${ }^{2}$ Luodong Forest District Office, Taiwan \\ Email: *yangsz@mail.npust.edu.tw, 126571583@yahoo.com.tw,v9320032@gmail.com
}

How to cite this paper: Yang, S.-Z., Chen, P.-H. and Chen, J.-J. (2019) Cambial Variations of Three Lianoid Genera, Akebia, Stauntonia, and Sabia (Lardizabalaceae and Sabiaceae), in Taiwan. American Journal of Plant Sciences, 10, 545-554.

https://doi.org/10.4236/ajps.2019.104039

Received: March 18, 2019

Accepted: April 15, 2019

Published: April 18, 2019

Copyright $\odot 2019$ by author(s) and Scientific Research Publishing Inc. This work is licensed under the Creative Commons Attribution International License (CC BY 4.0).

http://creativecommons.org/licenses/by/4.0/

\begin{abstract}
Descriptions of the cambial variants of the lianoids in two families, Lardizabalaceae and Sabiaceae, were lacking in Taiwan. This study aimed to diagnose the stem characteristics of seven lianoid species from these two families to update existing knowledge. Specifically, the transverse sections of fresh stems were diagnosed to generate a key. The results showed that all seven species develop one of ten cambial variant types, viz. axial vascular elements in segments. Of these species, Sabia swinhoei Hemsley, Stauntonia obovata Hemsley, and $S$. obovatifoliola Hayata formed secondary rays. The thick and successive periderm was apparent in Stauntonia obovata and S. obovatifoliola at older stem. The sclerenchyma ring was continuous or discontinuous in two genera (Akebia and Stauntonia), but was absent in Sabia. Four diagnostic features could be used to distinguish Lardizabalaceae and Sabiaceae; namely, the periderm, cortical sclerenchyma, vessel arrangement, and cortex ducts. The cambial variations documented for these seven lianoid species in Taiwan update existing information, facilitating comparisons between Lardizabalaceae and Sabiaceae.
\end{abstract}

\section{Keywords}

Cambium, Lardizabalaceae, Parenchyma, Sabiaceae, Secondary Ray

\section{Introduction}

The family Lardizabalaceae contains approximately seven genera and 40 species that are mainly distributed in E Asia [1] [2] [3], of which five species from two 
genera are found in Taiwan [4]. The family Sabiaceae contains approximately 66 species from three genera that are distributed in tropical and East Asia, as well as Central and South America [4] [5]. Six species from two of these genera are found in Taiwan [6]. Lardizabalaceae and Sabiaceae contain scandent (climbing) genera. In comparison, the species of Lardizabalaceae found in Taiwan are lianoid (woody vines), including the species from the genera Akebia Decaisne and Stauntonia de Candolle. Furthermore, all species of Sabiaceae are woody, but only the genus Sabia Colebr. is lianoid. Variation in the activity of vascular bundles leads to unusual variation in the distribution patterns of xylem and phloem, which influences stem shape [7]. One cambial variant has been documented in Akebia and Stauntonia, namely axial vascular elements in segments [8]; however, the types of cambial variants in Sabiaceaere are mainly poorly documented.

The woody morphological characteristics of lianoids in the Lardizabalaceae and Sabiaceae families include the primary form of vascular bundles maintained by wider rays. Specific characteristics include distinct growth rings, dimorphic vessels and porous rings. Vessel diameter is $>100 \mu \mathrm{m}$ for large vessels and $25-40$ $\mu \mathrm{m}$ for small vessels, while vessel density is $100-200 \mathrm{~mm}^{2}$. Large vessels tend to be solitary, while small vessels tend to be grouped. The axial parenchyma is vasicentric paratracheal, and occasionally apotracheal. The axial parenchyma can be diffuse or form aggregates, with distinct ray dilatations [9] [10].

For example, the interfascicular area of Akebia quinata Decne. (Lardizabalaceae) is sunken compared to fascicular areas. This phenomenon results in the stem cambium exhibiting slower activity in xylem ray areas. Sclerenchyma that forms in phloem ray areas can extend into xylem rays, and is interconnected outwardly with cortical sclerenchyma [9]. The species A. trifoliata (Thunb.) Koidz. has a growth ring, large unlignified rays at the transverse section of the periphery, and a belt of sclerenchyma below the phellogen [10]. The diagnostic features of Stauntonia hexapetala Decasn. include ray dilatations in the secondary phloem, and a group of sclerenchyma in the cortex area [10]. S. hexaphylla Decne has a growth ring, numerous vessels in earlywood and narrower and poor vessels in latewood [9]. The growth ring of Sabia japonica Maxim. (Sabiaceae) is type 3 , whereby vessels are at least twice as wide in earlywood compared to latewood [11].

Several authors have claimed that the lianoids of Lardizabalaceae and Sabiaceae are similar. The family Lardizabalaceae is placed in Ranunculales (Berberidales) [9]. There is much controversy over us whether this family is related toRutales (Sapindales) [9] or Proteales [3]. The family Sabiaceae is placed in Proteales; however, Sabiaceae is placed in Sabialesrather than Proteales [10]. Although the wood anatomy of $A$. quinata, A. trifoliata, $S$. hexapetala, $S$. hexaphylla and $S$. japonica has been described previously, cambial variations of more lianoids from Lardizabalaceae and Sabiaceae in Taiwan are needed. Such information would allow the identification of distinctive features, providing more evidence to advance phylogenetic studies. 


\section{Materials and Methods}

\subsection{Research Materials}

From 2015 to 2017, multiple samples of seven species, Akebia chingshuiensis T. Shimizu, Akebia longeracemosa Matsum, Stauntonia obovata Hemsley, Stauntonia obovatifoliola Hayata, Stauntonia purpurea Y. C. Liu \& F. Y. Lu, Sabia swinhoei Hemsley, and Sabia transarisanensis Hayata were collected. Stems with a lignified epidermis were selected to compare and identify structural variations using known secondary growth characteristics for their transections. Out of these species, $A$. chingshuiensis, $S$. purpurea, and $S$. transarisanensis are endemic species of Taiwan [4] [6] [12].

\subsection{Research Methods}

For each species, only one sample, exhibiting clear cambial variations that were easy to observe, was selected to photograph and describe. The fresh materials were cut into pieces of about $5 \mathrm{~cm}$ long. A flat, freehand cross-section of each stem was made with a razor blade. Cambial variation of the stems was measured and described based on certain parameters; namely, stem diameter $(\mathrm{mm})$, periderm thickness $(\mathrm{mm})$, periderm successive $(+/-)$, cortical sclerenchyma $(+/-)$, cortex with ducts $(+/-)$, semi-ring porous arrangement $(+/-)$, diffuse porous arrangement $(+/-)$, sclerenchyma rings $(+/-)$, sclerenchyma continuous $(+/-)$, xylem ray widening centrifugally $(+/-)$, secondary rays, collateral vascular bundle, xylem min-max width $(\mathrm{mm})$, xylem average width $(\mathrm{mm})$, xylem ray min-max width $(\mu \mathrm{m})$, xylem ray average width $(\mu \mathrm{m})$, vessel min-max diameter $(\mu \mathrm{m})$, vessel average diameter $(\mu \mathrm{m})$, and axial parenchyma. Cambial variants were identified based on Carlquist (1993) [11] [13] [14] [15] [16].

In the present study, vessel arrangement was defined as follows: If the vessels in early wood are 6 to $>10 \times$ larger in diameter than those in latewood, they are called ring-porous; if vessel diameter is constant throughout the growth ring, it is called diffuse-porous; and if vessels in early wood are 3 to $5 \times$ larger in diameter than those in the latewood, they are called semi-ring-porous [10]. Ray width size is defined by Chatta way (1933) [17]. This cambial variant type was derived from a single cambium, according to the report by Angyalossy et al. (2012) [14].

The stem surface was immediately photographed using a Nikon D7100 SLR digital camera (Lens AF Micro Nikon $60 \mathrm{~mm}$ 1:2.8D, Nikon Corporation, Tokyo, Japan). Quantitative anatomical traits were determined using Image-J software [18]. The specimens were dried in an oven $\left(60^{\circ} \mathrm{C}\right)$ for $4-5$ days, and were then stored at $-20^{\circ} \mathrm{C}$ for one week. All of the plant collections will be deposited in the herbarium, Provincial Pingtung Institute (PPI), National Pingtung University of Science and Technology, for subsequent identification. The nomenclature follows Flora of Taiwan Volume 2 [4] [6]. Information on specimens was assimilated, including the scientific name of species, herbarium, collector, voucher number, date, phenology, and locality. Morphological descriptions, photographs, and a key to the congeners were created to aid identification. 


\section{Results}

\subsection{Photographs and Explanations of Cambial Variants}

Information on the voucher specimens of the seven species from the two families, Lardizabalaceae and Sabiaceae, are presented (Table 1). In general, these seven species develop axial vascular elements in segments. The xylems are separated by broad rays ( $0.1-0.2 \mathrm{~mm}$ width) and moderately broad rays ( $0.05-0.1$ $\mathrm{mm}$ width). Some of the morphological characteristics of these two families were similar, including the presence of solitary vessels solitary, vessel dimorphism, and round stem transverse type.

Of these three genera, Akebia and Stauntonia, developed discontinuous (Figure 1) and continuous (Figure 2, Figure 3) sclerenchyma, respectively. The Sabia genus lacked this characteristic. The stems of the Stauntonia genus tended to develop a thick periderm, that was successive or non-successive around the stem (Figure 2, Figure 3). The thickness of the periderm was relative to the old stem. The periderm of $S$. obovatifoliola was approximately $0.2-1.9 \mathrm{~mm}$ thick, with a stem diameter of approximately $13.2 \mathrm{~mm}$ (Table 2, Figure 3(a)). The stem diameter of $S$. obovata and $S$. purpurea was approximately $25.7 \mathrm{~mm}$ and $12.8 \mathrm{~mm}$, with periderms of $2.40-4.60 \mathrm{~mm}$ and $0.07-0.54 \mathrm{~mm}$ thickness, respectively. Rays that widened centrifugally were clearly visible in $S$. swinhoei, $S$. transarisanensis (Figure 4), and $S$. obovatifoliola (Figure 3(a)). Out of the seven species, $S$. swinhoei, S. obovata and $S$. obovatifoliola formed 2 - 3 secondary rays through the proliferation of parenchyma.

Out of all the characteristics measured and described (Table 2), S. obovatifoliola was the largest for four features, including the average width of the xylem $(0.63$ $\pm 0.20 \mathrm{~mm})$, average width of xylem ray $(195 \pm 0.68 \mu \mathrm{m})$, and average diameter of vessels $(108 \pm 35 \mu \mathrm{m})$. The diameter of the largest vessels was approximately $5 \times$ larger than that of the smallest vessels (Table 2), showing that the diameter of vessels is subject to dimorphism (Figure 3(a)). The vessel arrangement of Lardizabalaceae was semi-ring-porous, whereas that of Sabiaceae was diffuse-porous.

Table 1. Collections of the seven species from the three genera Akebia, Stauntonia, and Sabia deposited in the Herbarium of Provincial Pingtung Institute (PPI) referred to in this study.

\begin{tabular}{|c|c|c|c|c|c|c|}
\hline Scientific name & Herbarium & Collector & $\begin{array}{l}\text { Voucher } \\
\text { number }\end{array}$ & Date & Phenology & Locality \\
\hline Akebia chingshuiensis & PPI & P. H. Chen & 1109 & May & fruits & Hsinchu County, Cinsbu \\
\hline Akebia longeracemosa & PPI & $\begin{array}{l}\text { S. T. Chiu, S. C. Mou } \\
\text { \& K. C. Yang }\end{array}$ & 6238 & May & flowers & $\begin{array}{l}\text { Hualien County, Hoping } \\
\text { Forest road }\end{array}$ \\
\hline Stauntonia obovata & PPI & Y. P. Liu & 026 & October & fruits & $\begin{array}{l}\text { Taitung County, Dazan } \\
\text { forest station }\end{array}$ \\
\hline Stauntonia obovatifoliola & PPI & P.H. Chen & 293 & March & flowers & $\begin{array}{l}\text { Taitung County, Dazan } \\
\text { forest station }\end{array}$ \\
\hline Stauntonia purpurea & PPI & $\begin{array}{l}\text { S. T. Chiu, S. C. Mou } \\
\text { \& K. C. Yang }\end{array}$ & 6190 & May & flowers & $\begin{array}{l}\text { Hualien County, Hoping } \\
\text { Forest road }\end{array}$ \\
\hline Sabia swinhoei & PPI & P.H. Chen & 478 & August & fruits & Pingtung County, Chenlishan \\
\hline Sabia transarisanensis & PPI & S. Z. Yang & 26551 & May & Flowers and fruits & Kaohsiung County, Tienchi \\
\hline
\end{tabular}


Table 2. Morphological characteristics of stem transverse section of five Lardizabalaceae species and two Sabiaceae species in Taiwan.

\begin{tabular}{|c|c|c|c|c|c|c|c|}
\hline \multicolumn{6}{|c|}{ Lardizabalaceae } & \multicolumn{2}{|c|}{ Sabiaceae } \\
\hline Characters & $\begin{array}{c}\text { Akebia } \\
\text { chingshuiensis }\end{array}$ & $\begin{array}{c}\text { Akebia } \\
\text { longeracemosa }\end{array}$ & $\begin{array}{c}\text { Stauntonia } \\
\text { obovata }\end{array}$ & $\begin{array}{c}\text { Stauntoniaobo } \\
\text { vatifoliola }\end{array}$ & $\begin{array}{l}\text { Stauntonia } \\
\text { purpurea }\end{array}$ & $\begin{array}{c}\text { Sabia } \\
\text { swinhoei }\end{array}$ & $\begin{array}{c}\text { Sabia } \\
\text { transarisanensis }\end{array}$ \\
\hline Stem diameter $(\mathrm{mm})$ & 6.2 & 4.4 & 6.9 & 13.2 & 6.7 & 16.6 & 13 \\
\hline Periderm thick (mm) & $0.04-0.14$ & $0.02-0.15$ & $0.07-0.38$ & $0.20-1.90$ & $0.05-0.36$ & - & - \\
\hline Periderm successive (+/-) & + & - & + & + & + & - & - \\
\hline Cortical sclerenchyma $(+/-)$ & + & + & + & + & + & - & - \\
\hline Cortex with ducts $(+/-)$ & - & - & - & - & - & + & + \\
\hline Semi-ring-porous & + & + & + & + & + & - & - \\
\hline Diffuse-porous & - & - & - & - & - & + & + \\
\hline Sclerenchyma rings $(+/-)$ & + & + & + & + & + & - & - \\
\hline Sclerenchyma continuous $(+/-)$ & + & - & + & + & + & - & - \\
\hline $\begin{array}{l}\text { Xylem rays widening } \\
\text { centrifugally }(+/-)\end{array}$ & - & - & - & + & - & + & + \\
\hline Secondary rays (+/-) & - & - & + & + & - & + & - \\
\hline $\begin{array}{l}\text { Collateral vascular } \\
\text { bundle number }\end{array}$ & 29 & 20 & 35 & 30 & 35 & 19 & 25 \\
\hline Xylem min-max width (mm) & $0.13-0.60$ & $0.14-0.57$ & $0.14-0.47$ & $0.19-1.00$ & $0.20-0.43$ & $0.49-1.31$ & $0.29-1.62$ \\
\hline $\begin{array}{l}\text { Xylem average width } \\
(\text { mean } \pm \mathrm{SD})(\mathrm{mm})\end{array}$ & $\begin{array}{c}0.39 \pm 0.12 \\
(\mathrm{n}=29)\end{array}$ & $\begin{array}{c}0.41 \pm 0.11 \\
(\mathrm{n}=20)\end{array}$ & $\begin{array}{c}0.34 \pm 0.10 \\
(\mathrm{n}=35)\end{array}$ & $\begin{array}{c}0.63 \pm 0.20 \\
(\mathrm{n}=30)\end{array}$ & $\begin{array}{c}0.32 \pm 0.06 \\
(\mathrm{n}=35)\end{array}$ & $\begin{array}{l}0.95 \pm 0.31 \\
\quad(\mathrm{n}=10)\end{array}$ & $\begin{array}{c}0.90 \pm 0.38 \\
(\mathrm{n}=22)\end{array}$ \\
\hline Xylem ray min-max width $(\mu \mathrm{m})$ & $37-119$ & $22-81$ & $19-114$ & $69-337$ & $12-143$ & $114-253$ & $69-221$ \\
\hline $\begin{array}{l}\text { Xylem ray average width } \\
\quad(\text { mean } \pm \mathrm{SD})(\mu \mathrm{m})\end{array}$ & $\begin{array}{l}72 \pm 19 \\
(\mathrm{n}=29)\end{array}$ & $\begin{array}{l}54 \pm 19 \\
(\mathrm{n}=20)\end{array}$ & $\begin{array}{l}63 \pm 23 \\
(\mathrm{n}=35)\end{array}$ & $\begin{array}{l}195 \pm 68 \\
(\mathrm{n}=30)\end{array}$ & $\begin{array}{l}59 \pm 23 \\
(\mathrm{n}=35)\end{array}$ & $\begin{array}{l}177 \pm 34 \\
(\mathrm{n}=19)\end{array}$ & $\begin{array}{l}156 \pm 31 \\
(\mathrm{n}=25)\end{array}$ \\
\hline $\begin{array}{l}\text { Vessel min-max diameter } \\
\qquad(\mu \mathrm{m})(\mathrm{n}=50)\end{array}$ & $27-143$ & $26-139$ & $26-143$ & $53-195$ & $17-103$ & $13-78$ & $53-147$ \\
\hline $\begin{array}{l}\text { Vessel average diameter } \\
(\mathrm{mean} \pm \mathrm{SD})(\mu \mathrm{m})(\mathrm{n}=50)\end{array}$ & $74 \pm 25$ & $78 \pm 29$ & $88 \pm 28$ & $108 \pm 35$ & $52 \pm 19$ & $33 \pm 12$ & $81 \pm 16$ \\
\hline Axial parenchyma & vasicentric & vasicentric & vasicentric & $\begin{array}{c}\text { vasicentric } \\
\text { scanty and few } \\
\text { diffuse }\end{array}$ & $\begin{array}{l}\text { vasicentric, } \\
\text { confluent }\end{array}$ & $\begin{array}{l}\text { vasicentric, } \\
\text { confluent }\end{array}$ & vasicentric \\
\hline
\end{tabular}

Note: +/-: prescence/absent; minimum-maximum: min-max.

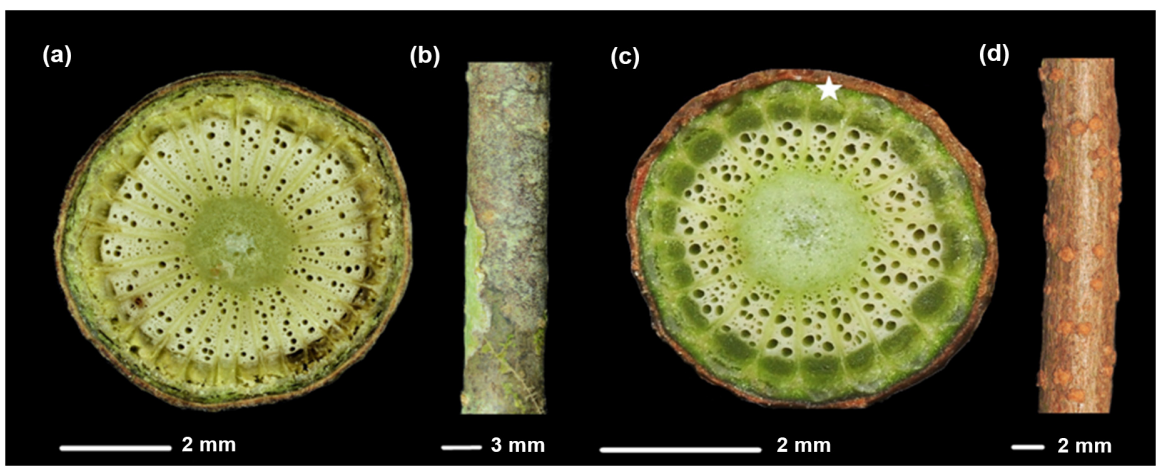

Figure 1. Transverse section of the stem and epidermis of Akebia chingshuiensis T. Shimizu (a)-(b), and Akebia longeracemosa Matsum. (c)-(d) (Lardizabalaceae). (a) Enlargement of cortical sclerenchyma extending into xylem rays; (b) Stem round, epidermis covered with few lenticels and glabrous; (c) Discontinuous gray sclerenchyma (star), phloem deep-green in color; (d) Stem round, epidermis covered numerous lenticels. 


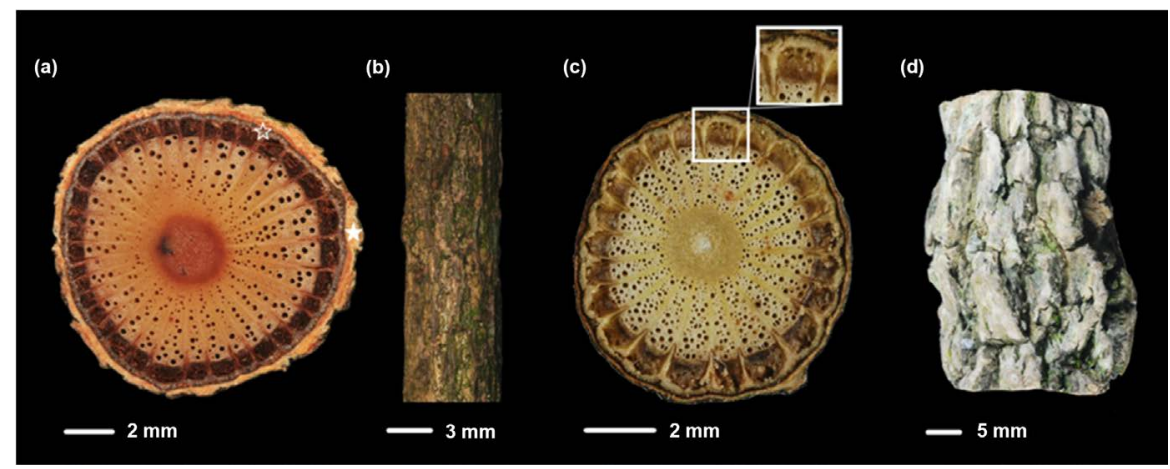

Figure 2. Transverse sections of stem and epidermis of Stauntonia obovata Hemsley from three specimens (Lardizabalaceae). (a) Section description from the pith to the outside of the stem: pith red in color, semi-ring porous, phloem rectangular in shape and deep-brown when dried, white cortical sclerenchyma and black sclerenchyma ring (white star), stem surrounded by periderm (solid white star); (b) Epidermis glabrous at younger stage; (c) Enlargement of cortical sclerenchyma connected with plate of sclerenchyma that formed in the phloem rays; (d) Stem diameter is approximately $2.6 \mathrm{~cm}$, surrounded by a $2.4-4.6 \mathrm{~mm}$ thick periderm.

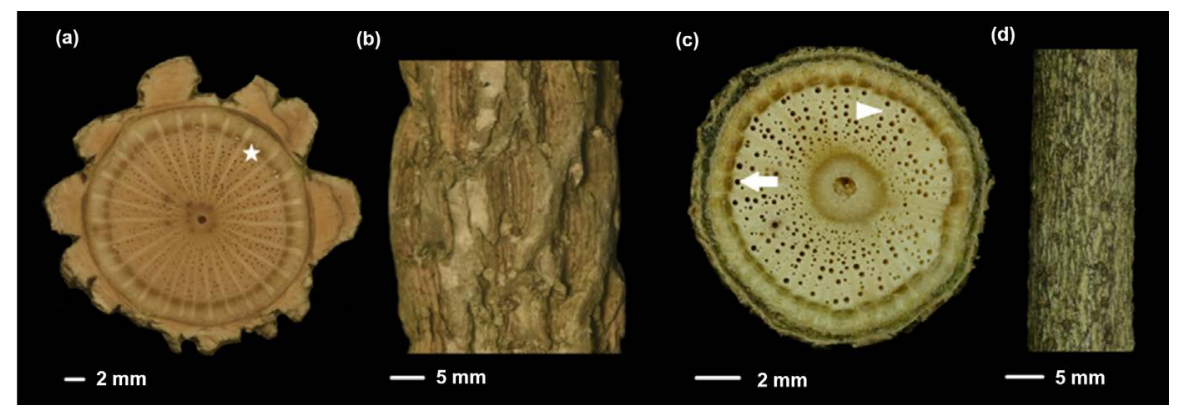

Figure 3. Transverse section of stem and epidermis of Stauntonia obovatifoliola Hayata (a), (b) and Stauntonia purpurea Y. C. Liu \& F. Y. Lu (c), (d) (Lardizabalaceae). (a) Numberof collateral vascular bundle (white star) approximately 30 , and stem covered by 0.2 - $1.9 \mathrm{~mm}$ thick periderm; (b) Stem surrounded by furrowed thick periderm; (c) Vessel dimorphism; showing the smallest (white arrow head) and largest (white arrow) vessels; (d) Epidermis broken ridges, pale-gray in color.

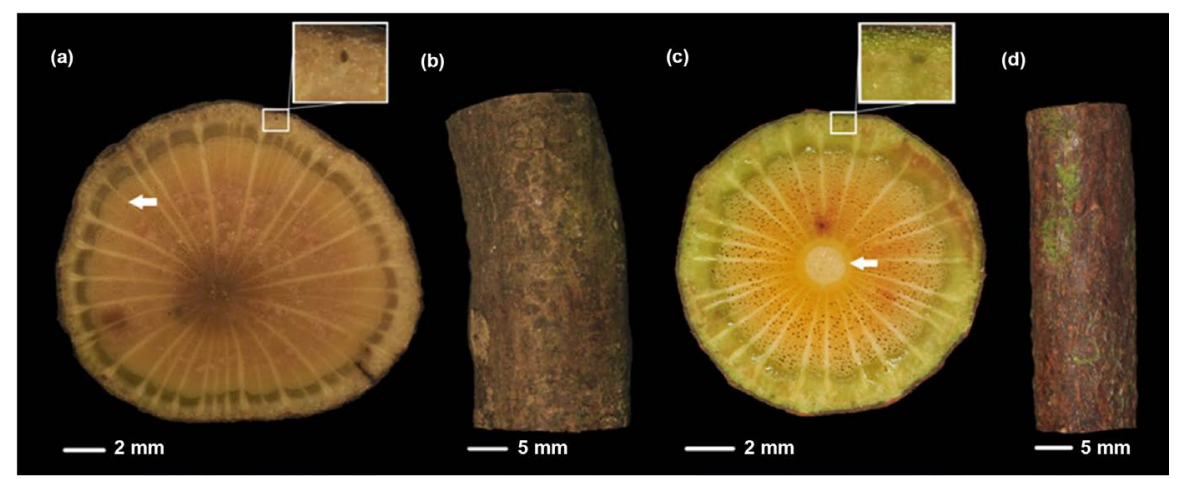

Figure 4. Transverse section of stem and epidermis of Sabia swinhoei Hemsl. (a), (b) and Sabia transarisanensis Hayata (c), (d) (Sabiaceae). (a) Secondary rays (split strips) (white arrow), enlargement of cortex with ducts; (b) Epidermis glabrous, gray in color; (c) Primary xylem ring (white arrow), clearly located around the pith, enlargement of cortex with ducts; (d) Epidermis glabrous, brown-green in color. 
All five species of Lardizabalaceae were of the axial parenchyma type, whereby the vessels were surrounded by vasicentric paratracheal. However, the vessels of S. obovatifoliola and $S$. purpurea developed scandy, diffuse, and confluent parenchyma. The vessels of the two Sabiaceae species were surrounded by vasicentric and confluent parenchyma.

\subsection{Characterization of Species}

A key to the five Lardizabalaceae species and two Sabiaceae species in Taiwan is presented here, based on the characteristics of the bark and anomalous vascular bundles.

1) Stem without periderm; cortex with ducts

-1) Stem with periderm

2) Vessels about $33 \mu \mathrm{m}$ in diameter; with secondary rays Sabia swinhoei

-2) Vessel about $81 \mu \mathrm{m}$ in diameter; without secondary rays Sabia transarisanensis

3) With 2 - 3 secondary rays

-3) Without 2-3 secondary rays 5

4) Periderm $0.2-1.9 \mathrm{~mm}$ thick

Stauntonia obovatifoliola

-4) Periderm $0.07-0.38 \mathrm{~mm}$ thick Stauntonia obovata

5) Periderm non-successive Akebia longeracemosa

-5) Periderm successive

6) Axial parenchyma surrounded by vasicentric Akebia chingshuiensis

-6) Axial parenchyma surrounded by vasicentric and confluent Stauntonia purpurea

\section{Discussion}

The vessel diameter of the five Lardizabalaceae species found in Taiwan ranges from 103 to $195 \mu \mathrm{m}$ for larger vessels and 17 to $53 \mu \mathrm{m}$ for small vessels, supporting the description in [10]. Cariquist (1984) [9] stated that the periderm is thick and successive in old stems of Lardizabalaceae. In this study, the five species of Lardizabalaceae had successive (Figure 2(d)) or non-successive periderms, with this characteristic not being found in Sabiaceae. Thus, the characteristics of periderm could be used to differentiate these two genera. Phloem rays in the stems of $A$. quinata contained plates of sclerenchyma and were interconnected outwardly with cortical sclerenchyma [9]. These features were clearly detectable in Akebia and Stauntonian (Figures 1-3), but were not found in Sabia (Figure 4).

The transverse sections of $S$. obovatifoliola and $S$. swinhoei stems showed the presence of 2 - 3 secondary rays (Figure 3(a), Figure 4(a)), which arose through the proliferation of parenchyma between some collateral vascular bundle. This feature was recorded in the species Aristolochia macrophylla of Aristolochiaceae [10] and the genus Cyclea of Menispermaceae [15]. These condary ray is also termed a split strip, which forms near the periphery with increasing stem di- 
ameter. However, the formation of secondary rays might depend on the diameter of the stem, requiring further investigation.

The average vessel diameter of $A$. chingshuiensis and $A$. longeracemosa was $74 \mu \mathrm{m}$ and $78 \mu \mathrm{m}$ (Table 2), respectively. These values were similar to those obtained for A. trifoliata $(52 \mu \mathrm{m})$ reported in [9]. The scientific name $S$. hexaphylla was treated as the synonym of $S$. obovatifoliola [4]. The average vessel diameter of $S$. obovatifoliola was $108 \mu \mathrm{m}$ larger than that of $S$. hexaphylla $(52 \mu \mathrm{m})$, as recorded by Cariquist (1984) [9]. Because vessel density, size, and xylem length varied across individuals, classification was more difficult. In particular, differences in size might be relative to the growing regions. Only $S$. swinhoi and $S$. transarisanensis had a cortex with ducts (Figure 4). This diagnostic characteristic was not identified by previous reports. Thus, four diagnostic features (periderm, cortical sclerenchyma, vessel arrangement, and cortex ducts) may be used to distinguish Lardizabalaceae and Sabiaceae (Table 2).

The family Sabiaceae has wedge-shaped phloem rays [19]; however, this feature was not apparent in the two Sabia species from Taiwan. There remains controversy over whether Sabiaceaeis related to Rutales (Sapindales) [9], Proteales [3], or Sabiales [10]. The characteristics that were measured and described in this study could be used to compare functions and provide evidences to resolve systematic problems. Therefore, further study on the woody anatomy of Lardizabalaceae and Sabiaceaeis required.

\section{Conclusion}

Information about cambial variation in the three genera, Akebia, Stauntonia, and Sabia provided more evidence about congeners. In addition, a key was developed to aid the identification of these species. Seven species from two families, Lardizabalaceae and Sabiaceae, develop axial vascular elements in segments, which are separated by wider rays. Second rays were detected in older specimens of $S$. swinhoei, S. obovata, and S. obovatifoliola. Of these, the stems of $S$. obovata and $S$. obovatifoliola develop a thick periderm. The sclerenchyma ring is discontinuous or continuous in the genera, Akebia and Stauntonia, and was absent in the Sabia genus. The vessel arrangement, periderm, cortex with ducts, and cortical sclerenchyma in Lardizabalaceae differed to that in Sabiaceae. Thus, these four diagnostic features could be used to distinguish these two families. In conclusion, the information presented here could be used to help resolve the classification of Lardizabalaceae and Sabiaceae.

\section{Acknowledgements}

The authors thank the staff working in the Herbarium of PPI, National Pingtung University of Science and Technology, for providing assistance in the field and for providing the fresh stem material about the families Lardizabalaceae and Sabiaceae. The authors thank the anonymous reviewers for providing comments that improved an earlier draft of this manuscript. 


\section{Conflicts of Interest}

The authors declare no conflicts of interest regarding the publication of this paper.

\section{References}

[1] Mabberley, D.J. (1997) The Plant-Book: A Portable Dictionary of the Vascular Plants. Cambridge University Press, Cambridge.

[2] Chen, D.Z. and Shimizu, T. (2001) Lardizabalaceae. In: Wu, Z.Y., Raven, P.H. and Hong, D.Y. Eds., Flora of China, Science Press, Beijing, 440-454.

[3] Christenhusz, M.J.M. and Byng, J.W. (2016) The Number of Known Plants Species in the World and Its Annual Increase. Phytotaxa, 261, 201-217. https://doi.org/10.11646/phytotaxa.261.3.1

[4] Qin, H.N. (1996) Lardizabalaceae. In: Huang, T.C. Ed., Flora of Taiwan, 2nd Edition, Department of Botany National Taiwan University, Taipei, 586-590.

[5] Guo, L.X. and Brach, A.R. (2007) Sabiaceae. In: Wu, Z.Y., Raven, P.H. and Hong, D.Y., Eds., Flora of China, Science Press \& Missouri Botanical Garden, 25-42.

[6] Li, H.L. (1993) Sabiaceae. In: Huang, T.C., Ed., Flora of Taiwan, 2nd Edition, Department of Botany National Taiwan University, Taipei, 611-615.

[7] Beck, C.B. (2011) An Introduction to Plant Structure and Development: Plant Anatomy for the Twenty-First Century. 2nd Edition, Cambridge University Press, Cambridge.

[8] Angyalossy, V., Pace, M.R. and Lima, A.C. (2015) Liana Anatomy: A Broad Perspective on Structural Evolution of the Vascular System. In: Schnitzer, S.A., Bongers, F., Burnham, R.J. and Putz, F.E. Eds., Ecology of Lianas, Wiley Blackwell, West Sussex, U K, 253-287. https://doi.org/10.1002/9781118392409.ch19

[9] Carlquist, S. (1984) Wood and Stem Anatomy of Lardizabalaceae with Comments on the Vining Habitat, Ecology and Systematics. Botanical Journal Linnean Society, 88, 257-277. https://doi.org/10.1111/j.1095-8339.1984.tb01575.x

[10] Schweingruber, F.H., Börner, A. and Schulze, E.-D. (2013) Introduction to Volume 2. In: Atlas of Stem Anatomy in Herbs, Shrubs and Trees, Springer-Verlag, Berlin, Heidelberg, 1-4. https://doi.org/10.1007/978-3-642-20435-7_1

[11] Carlquist, S., Morrell, P.L. and Manchester, S.R. (1993) Wood Anatomy of Sabiaceae (S. L.); Ecological and Systematic Implications. A Journal of Systematic and Evolutionary Botany, 13, 521-549.

[12] Shimizu, T. (1961) Taxonomic Study of the Genus Akebia with Special Reference to a New Species from Taiwan. Quarterly Journal of Taiwan Museum, 14, 195-202.

[13] Carlquist, S. (2001) Cambial Variants (Anomalous Secondary Growth). In: Comparative Wood Anatomy, Springer-Verlag Press, Berlin, Germany, 271-295. https://doi.org/10.1007/978-3-662-04578-7_8

[14] Angyalossy, V., Angeles, G., Pace, M.R., Lima, A.C., Dias-Leme, C.L., Lohmann, L.G. and Madero-Vega, C. (2012) An Overview of the Anatomy, Development and Evolution of the Vascular System of Lianas. Plant Ecological and Diversity, 5, 167-182. https://doi.org/10.1080/17550874.2011.615574

[15] Yang, S.Z. and Chen, P.H. (2015) Classifying Taiwan Lianas with Radiating Plates of Xylem. Taiwania, 60, 151-159.

[16] Yang, S.Z. and Chen, P.H. (2016) Cambial Variants in the Family Menispermaceae 
in Taiwan. American Journal Plant Science, 7, 841-854.

https://doi.org/10.4236/ajps.2016.76080

[17] Chattaway, M.M. (1933) Ray Development in the Sterculiaceae. Forestry, 7, 93-108. https://doi.org/10.1093/oxfordjournals.forestry.a063360

[18] Ferreira, T. and Rasband, W. (2011) The ImageJ User Guide Version 1.44. http://rsbweb.nih.gov/ij/docs/user-guide.pdf

[19] Nandi, O.I., Chase, M.W. and Endress, P.K. (1998) A Combined Cladistic Analysis of Angiosperms Using rbcL and Non-Molecular Data Sets. Annals of the Missouri Botanical Garden, 85, 137-214. https://doi.org/10.2307/2992003 